\title{
Perioperative epidural analgesia is not associated with increased survival from renal cell cancer, but overall survival may be improved: a retrospective chart review \\ L'analgésie péridurale périopératoire n'est pas associée à une augmentation de la survie après un cancer des cellules rénales, mais la survie globale pourrait être améliorée : une analyse de dossiers rétrospective
}

\author{
Evan Kovac, MD, CM, FRCSC • Farhad Firoozbakhsh, MD • Homayoun Zargar, MD • \\ Amr Fergany, MD, FACS · Hesham Elsharkawy, MD, MSc \\ Received: 29 March 2016/Revised: 10 February 2017/Accepted: 11 April 2017/Published online: 17 April 2017 \\ (C) Canadian Anesthesiologists' Society 2017
}

\begin{abstract}
Purpose We investigated the possible association between perioperative epidural and both cancer-specific survival (CSS) and overall survival (OS) in patients undergoing partial or radical nephrectomy for localized renal cell carcinoma $(R C C)$.

Methods $A$ retrospective chart review was performed on patients who underwent complete surgical resection of localized RCC from 1994-2008 at our institution. Baseline demographics and pathological and survival data were collected. Patients with clinically or pathologically positive lymph nodes or metastatic disease at the time of surgery were excluded. Patients with pathologically positive surgical margins were also excluded. Patients were divided into two groups, systemic analgesia and epidural analgesia. Multivariable Cox regression analysis
\end{abstract}

Electronic supplementary material The online version of this article (doi:10.1007/s12630-017-0875-3) contains supplementary material, which is available to authorized users.

E. Kovac, MD, CM, FRCSC · H. Zargar, MD ·

A. Fergany, MD, FACS

Glickman Urological \& Kidney Institute, Cleveland Clinic

Foundation, Cleveland, OH, USA

F. Firoozbakhsh, MD · H. Elsharkawy, MD, MSc ( $\square)$ Anesthesiology Institute and Outcomes Research, Cleveland Clinic Foundation, Cleveland, OH, USA

e-mail: elsharh@ccf.org

H. Elsharkawy, MD, MSc

CCLCM of Case Western Reserve University, Cleveland, OH, USA was used to determine CSS and OS, and survival curves were generated using the Kaplan-Meier method.

Results Four hundred thirty-eight patients were included in the analysis. Baseline characteristics of both groups were similar. Median follow-up was 77 months. On multivariable analysis, patient age (hazard ratio [HR], 1.04; 95\% confidence interval [CI], 1.02 to 1.07), epidural status (HR, 0.5; 95\% CI, 0.4 to 0.8 ), year of surgery (HR, 0.9; 95\% CI, 0.89 to 0.95), and pathologic T-stage ( $p T$-stage) $\geq 2$ (pTstage2: $H R, 2.2 ; 95 \% C I, 1.2$ to 4.1 and pT-stage3: $H R, 3.1$; 95\% CI, 2.0 to 4.7) were independent predictors of OS. Nevertheless, epidural status did not significantly predict CSS $(P=0.73)$, while T-stage and year of surgery maintained their respective predictive significance. Tumour grade did not significantly affect OS or CSS.

Conclusions Our retrospective analysis suggests that epidural at the time of surgical excision of localized RCC does not significantly impact CSS. Nevertheless, use of epidural was associated with significantly improved OS. Future prospective clinical and laboratory studies are warranted in order to characterize these associations further and determine the underlying mechanisms.

\section{Résumé}

Objectif Nous avons examiné l'association possible entre une péridurale périopératoire et la survie spécifique au cancer (SSC) ou la survie globale (SG) chez des patients subissant une néphrectomie partielle ou radicale en raison d'un hypernéphrome localisé.

Méthode Nous avons réalisé une analyse rétrospective des dossiers des patients ayant subi une résection 
chirurgicale totale d'un hypernéphrome localisé entre 1994 et 2008 dans notre institution. Les données démographiques et pathologiques de base ainsi que les données de survie ont été colligées. Les patients ayant des nouds lymphö̈des positifs d'un point de vue clinique ou pathologique ou une maladie métastatique au moment de la chirurgie ont été exclus de l'étude. Ont également été exclus les patients ayant des marges chirurgicales positives d'un point de vue pathologique. Les patients ont été divisés en deux groupes, soit analgésie systémique/intraveineuse et analgésie péridurale. Une analyse multivariée par régression de Cox a été utilisée afin de déterminer la SSC et la SG, et les courbes de survie ont été générées à l'aide de la méthode de Kaplan-Meier.

Résultats Quatre cent trente-huit patients ont été inclus dans l'analyse. Les caractéristiques de base des deux groupes étaient semblables. Le suivi médian était de 77 mois. Lors de l'analyse multivariée, l'âge du patient (rapport de risque [RR] 1,04; intervalle de confiance [IC] $95 \%, 1,02$ à 1,07), le statut péridural (RR, 0,5; IC $95 \%$, 0,4 à 0,8), l'année de la chirurgie (RR, 0,9; IC $95 \%, 0,89$ à $0,95)$ et le stade T pathologique (stade Tp) $\geq 2$ (stade Tp2 : RR, 2,2; IC $95 \%, 1,2$ à 4,1 et stade Tp3 : RR, 3,1; IC $95 \%$, 2,0 à 4,7) étaient des prédicteurs indépendants de $S G$. Toutefois, le statut péridural n'a pas prédit la SSC de façon significative $(P=0,73)$, alors que le stade $T$ et l'année de chirurgie ont maintenu leur importance prédictive respective. La classification histologique de la tumeur n'a pas affecté la SG et la SSC de façon significative.

Conclusion Selon notre analyse rétrospectiveune péridurale réalisée au moment de l'excision chirurgicale d'un hypernéphrome localisé n'a pas d'impact significatif sur la SSC. L'utilisation d'une péridurale était toutefois associée à une SG considérablement améliorée. D’autres études prospectives cliniques et de laboratoire sont nécessaires à l'avenir pour caractériser davantage ces associations et en déterminer les mécanismes sous-jacents.

Over the last several decades, expanding utilization of computed tomography, ultrasound, and magnetic resonance imaging has led to an increase in incidentally discovered renal masses as well as a significant stage migration towards earlier detection of more localized lesions. ${ }^{1}$ Surgical treatment through radical or partial nephrectomy is the mainstay of management and is the only curative treatment for renal cell carcinoma (RCC). Nevertheless, resection of the primary lesion can itself be associated with the release of cancer cells into the lymphatic system and bloodstream and act as the source of metastatic disease, as has been shown in both animal and human models. ${ }^{2,3}$
Previous work has shown that RCC is an immunoresponsive malignancy, and immune-based therapies have shown to prolong survival in metastatic RCC (mRCC), ${ }^{4-6}$ while others have shown that cytokinerelated therapies improve survival in mRCC. ${ }^{7,8}$ As a corollary, perioperative epidural (POE) analgesia has been shown to reduce postoperative pain and improve immune function in patients undergoing a variety of invasive surgical procedures. ${ }^{9-12}$ Regional anesthesia in the setting of oncologic surgery may have less deleterious short-term effects on the immune system, potentially decreasing cancer recurrence by attenuating the neuroendocrine stress response to surgery, reducing pain, minimizing opioid use, and decreasing pro-inflammatory cytokines. $^{13,14}$ Thus, the leading hypothesis that epidural analgesia confers benefit with regard to cancer recurrence is based on its ability to attenuate the immune suppression that accompanies surgical stress. There is currently a paucity of literature examining the relationship between POE and survival following complete surgical resection of localized RCC. We therefore endeavoured to evaluate the potential association between the use of POE and improved survival outcomes in patients undergoing open surgical resection of localized RCC.

\section{Methods}

After obtaining Cleveland Clinic Institutional Review Board approval, we performed a retrospective chart review of a prospectively collected database of patients who underwent surgical resection for clinically localized RCC at our institution from 1994-2008. This database has been utilized in previous publications from this institution. ${ }^{15}$ This study was not registered. Two authors (F.F. and E.K.) obtained patient details (including baseline demographics and tumour histology, grading, and staging) through electronic medical records (EMR), and a third author (H.E.) verified the data. A designated, registered nurse database manager then entered and continuously updated the records. Patients undergoing open radical or partial nephrectomy ( $\mathrm{RN}$ or $\mathrm{PN})$, without clinical or radiographic evidence of metastatic disease at the time of surgery, but with pathologically confirmed RCC (including all of its histological subtypes), were included in the study. Patients were excluded from the analysis if they underwent laparoscopic or robotic radical/partial nephrectomy (as epidurals are rarely required in these cases due to diminished analgesia requirements), underwent percutaneous thermal ablative therapy, or had positive surgical margins, non-malignant histology (e.g., angiomyolipoma, oncocytoma, benign cyst, etc.), or 
evidence of clinical or pathologic adrenal or lymph node involvement. Perioperative epidural status for each patient was obtained from billing codes and confirmed by reviewing the EMR. Patients were divided into two groups according to POE status-i.e., patients who received only perioperative systemic analgesia (SA group) only at the time of open radical/partial nephrectomy and patients who received POE, in addition to systemic analgesia, at the time of open radical/partial nephrectomy (EA group).

All epidural catheters were inserted in the thoracic region (from T-7 to T-10), and the anesthesiologist selected the precise anatomic level to match the planned incision. The intraoperative use of epidurals was determined by EMR review. Postoperative analgesia was managed with continuous infusions of bupivacaine combined with either morphine (1994-2004) or fentanyl (1995-2008). Epidural functionality was assessed immediately postoperatively in the recovery room, then daily by acute pain service team members. Epidural failure was defined as complete failure to attain any dermatomal analgesic coverage and/or conversion to alternative/systemic analgesic methods and discontinuation of the epidural catheter.

Postoperative opioid analgesia for SA patients was achieved by patient-controlled intravenous infusion and/or oral administration (hydromorphone, fentanyl, oxycodone, and rarely morphine).

The primary endpoints for the study were cancerspecific survival (CSS) and overall survival (OS), where CSS is defined as freedom from death from renal cell carcinoma, specifically, and OS is defined as freedom from death from all causes of mortality, including renal cell carcinoma. Secondary endpoints included median intraoperative blood loss and median hospital stay, in days. Other variables analyzed included age, sex, race, American Society of Anesthesiologists (ASA) class, year of surgery, pathologic T-stage (pT-stage) based on the American Joint Committee on Cancer classification and pathologic Fuhrman grade-the most popular and widely accepted systems for staging and grading of RCC, respectively. ${ }^{16,17}$ These patient- and disease-specific variables were chosen specifically because they are commonly associated with altered patient survival. ${ }^{18-21}$

Survival status for each patient was determined through the Social Security Death Index, while cause of death was obtained from the Ohio Death Index (a state-run data collection program that tracks deaths and causes of death derived from death certificates from the Ohio Department of Health in Columbus, OH, USA), EMR, and/or phone call to the patient's next of kin. Survival time was calculated from the date of surgery.

Differences in baseline characteristics between the groups were compared. Medians and quartiles were calculated for continuous variables, and $P$ values were obtained from the Wilcoxon rank-sum test. Frequencies and percentages were calculated for categorical variables, and $P$ values were obtained from the Chi square test.

In order to account for differences between the two groups, we performed a propensity score analysis of epidural on the matched cohort for both CSS and OS by logistic regression (Supplemental Figs 1 and 2 for CSS and OS, respectively; available as Electronic Supplementary Material). The variables used to calculate the propensity score included age, race, sex, ASA class, year of surgery, pT-stage, and pathologic Fuhrman grade. For OS, we identified 280 records with complete data on all matching variables: 162 were in the EA group and 118 were in the SA group. The matching algorithm ratio was $1: 1$, without replacement. For the OS analysis, we matched 118:118 for the EA group $v s$ the SA group. For the CSS analysis, the ratio was 112:112. All variables were balanced for the matched dataset at a significance level of 0.05 . All reported CSS and OS results are based on matched data.

Multivariable Cox regression analysis of matched patients was used to determine CSS and OS for the SA and EA groups using the aforementioned variables (age, sex, race, ASA class, year of surgery, use of intraoperative epidural, pT-stage, and pathologic Fuhrman grade), while CSS and OS survival curves comparing matched SA and EA groups were generated using the Kaplan-Meier method. All calculations were performed using Statistical Package for the Social Sciences (SPSS ${ }^{\circledR}$ ), version 21 (IBM Corp., Armonk, NY, USA). Data were considered statistically significant at a $P$ value of 0.05 .

\section{Results}

We identified 1,312 patients in our database who had undergone surgery for renal tumours during 1994-2008. Patients were excluded for one or several of the following reasons: underwent thermal ablative therapy $(n=122)$ or laparoscopic renal surgery $(n=305)$, non-malignant $(n=584)$ or non-renal cell carcinoma histology $(n=3)$, cT4 disease (i.e., the tumour has spread beyond Gerota's fascia-the fibrous layer that surrounds the kidney and nearby fatty tissue - or has grown into the adrenal gland, thereby denoting locally advanced disease) $(n=8)$, pathologically confirmed node-positive disease $(n=29)$, radiologically confirmed metastases at the time of surgery $(n=50)$, positive intraoperative surgical margins $(n=15)$. Thus, 874 patients were excluded, leaving 438 patients for the final analysis-203 patients in the SA group and 235 patients in the EA group. Overall survival data were available for all patients. Despite using the Social Security Death Index, Ohio Death Index, EMR, and 
phoning next of kin, cause of death information was not available for $28(6.4 \%)$ deceased patients (15 patients in the SA group and 13 in the EA group). These patients were excluded from the CSS analysis. Median [interquartile range (IQR)] follow-up time was 77 [37-122] mth (6.4 yr).

Baseline patient characteristics for the entire cohort, including ASA class and pathologic patient characteristics, were similar between the SA and EA groups, except for pathologic stage (Table 1). Pathologic stage information was not available for 84 and 75 patients in the SA and EA groups, respectively, as these patients underwent open partial nephrectomy, to which no T-staging is applied. Baseline patient characteristics for the CSS and OS matched cohorts are presented in Tables 1 and 2 Electronic Supplementary Material, respectively.

All operations were performed under general anesthesia. Intraoperative epidural infusions were used in 211/235 (90\%) EA patients, while almost all postoperative epidural infusions were functional among EA patients (229/235 [97\%]). For EA patients, epidural infusions consisted of fentanyl $2 \mu \mathrm{g} \cdot \mathrm{mL}^{-1}$ and $0.1 \%$ bupivacaine in $116(49 \%)$ patients, or morphine $100 \mu \mathrm{g} \cdot \mathrm{mL}^{-1}$ and $0.1 \%$ bupivacaine in $119(51 \%)$ patients. The median [IQR] duration of indwelling perioperative epidural was 3 [3-3] days.

Epidural usage increased over time. Among the $235 \mathrm{EA}$ patients, 74/235 (31\%) patients received epidurals for procedures performed up to and including 2001, while 161/ 235 (69\%) patients received epidurals for procedures performed after $2001(P<0.001)$. A cutoff year of 2001 was chosen to reflect the midpoint in time of our study population and to differentiate between epidural practices before and after that time.

Overall, 120 (59\%) and 86 (37\%) patients died in the unmatched SA and EA groups, respectively, during the study period. Median OS rates for the SA and EA groups were $105 \mathrm{mth}(8.8 \mathrm{yr}) \mathrm{vs} 187 \mathrm{mth}(15.6 \mathrm{yr})$, respectively (95\% CI, 74.1 to 135.9 and 121.6 to 252.4 , respectively). This translates to a $27 \%$ and $20 \%$ mortality rate at the median follow-up point for the SA and EA groups, respectively. The OS rates for SA patients at five and ten

Table 1 Baseline patient clinical and pathologic characteristics for the entire (unmatched) cohort

\begin{tabular}{|c|c|c|c|c|}
\hline & & SA $(n=203)$ & $\mathrm{EA}(n=235)$ & $P$ value \\
\hline Age, Median [IQR] & & 62 [54-69] & $62[53-68]$ & 0.60 \\
\hline Male, $n(\%)$ & & $133(65.5)$ & $141(60.0)$ & 0.24 \\
\hline Female, $n(\%)$ & & $70(34.5)$ & $94(40.0)$ & \\
\hline \multirow[t]{5}{*}{ Race, $n(\%)$} & Caucasian & $179(88.2)$ & $214(91.1)$ & 0.26 \\
\hline & African American & $16(7.9)$ & $14(6.0)$ & \\
\hline & Asian & $3(1.5)$ & $6(2.6)$ & \\
\hline & Hispanic & $2(1)$ & $1(0.4)$ & \\
\hline & Other/Unknown & $3(1.5)$ & $0(0)$ & \\
\hline \multirow[t]{6}{*}{ ASA Class, $n(\%)$} & I & $1(0.5)$ & $1(0.4)$ & 0.49 \\
\hline & II & $40(19.7)$ & $54(23.0)$ & \\
\hline & III & $159(78.3)$ & $176(74.9)$ & \\
\hline & IV & $0(0)$ & $2(0.8)$ & \\
\hline & $\mathrm{V}$ & $0(0)$ & $0(0)$ & \\
\hline & Unknown & $3(1.5)$ & $2(0.9)$ & \\
\hline \multirow[t]{3}{*}{ Pathologic Grade, $n(\%)$} & Low (Grades 1-2) & $75(36.9)$ & $108(45.9)$ & 0.06 \\
\hline & High (Grades 3-4) & $71(34.9)$ & $70(29.8)$ & \\
\hline & Unknown & $57(28.1)$ & $57(24.3)$ & \\
\hline \multirow[t]{4}{*}{ Pathologic Stage, $n(\%)$} & $T 1$ & $70(34.5)$ & $124(52.8)$ & 0.001 \\
\hline & $T 2$ & $18(8.9)$ & $8(3.4)$ & \\
\hline & $T 3$ & $42(20.7)$ & $38(16.2)$ & \\
\hline & $N / A$ & $73(35.9)$ & 75 (31.9) & \\
\hline \multirow[t]{6}{*}{ Histology, $n(\%)$} & Clear cell & $171(84.2)$ & $191(81.3)$ & 0.16 \\
\hline & Papillary & $26(12.8)$ & $26(11.0)$ & \\
\hline & Chromophobe & $4(1.9)$ & $13(5.5)$ & \\
\hline & Sarcomatoid & $0(0)$ & $1(0.4)$ & \\
\hline & Oncocytic & $2(0.9)$ & $1(0.4)$ & \\
\hline & Unclassified & $0(0)$ & $2(0.9)$ & \\
\hline
\end{tabular}

$\mathrm{ASA}=$ American Society of Anesthesiologists; $\mathrm{EA}=$ epidural analgesia; $\mathrm{SA}=$ systemic analgesia; $\mathrm{IQR}=$ interquartile range 
years were $61.1 \%$ (95\% CI, 54.5 to 67.7$)$ and $46.4 \%$ (95\% CI, 39.4 to 53.4), respectively. The OS rates for EA patients at five and ten years were $74.0 \%$ (95\% CI, 68.4 to 79.7) and $57.6 \%$ (95\% CI, 49.4 to 65.8$)$, respectively.

Kaplan-Meier analysis of matched patients revealed an improved OS for EA patients compared with SA patients, while we did not observe a statistically significant difference in CSS over time (Figs 1,2). On multivariable analysis of matched patients, epidural status (hazard ratio [HR], 0.5 ; $95 \% \mathrm{CI}, 0.4$ to 0.8 ), year of surgery (HR, 0.9; $95 \% \mathrm{CI}, 0.85$ to 0.96 ), and pT-stage $\geq 2$ (pT-stage $2: \mathrm{HR}$, 2.5; $95 \% \mathrm{CI}, 1.4$ to 4.5 and pT-stage $3: \mathrm{HR}, 3.1 ; 95 \% \mathrm{CI}$, 2.0 to 4.8 ) were independent predictors of OS, while highgrade (Fuhrman grade III-IV) vs low-grade (Fuhrman grade I-II) disease was not (HR, 0.9; 95\% CI, 0.6 to 1.4). Nevertheless, epidural status did not predict better CSS (HR, 0.7; 95\% CI, 0.4 to 1.2 ), while year of surgery (HR, $0.9 ; 95 \%$ CI, 0.80 to 0.96 ) and pT-stage $\geq 2$ predicted CSS (pT-stage2: HR, 3.8; 95\% CI, 1.4 to 10.7 and pT-stage3: HR, 8.1; 95\% CI, 3.7 to 18.0). High-grade vs low-grade disease did not significantly predict CSS (HR, 1.6; 95\% CI, 0.8 to 3.2 ). When factoring intraoperative epidural use, the OS advantage was maintained on multivariable analysis (HR, 0.6; $95 \%$ CI, 0.4 to $0.9 ; P=0.006$ ), while CSS was not significantly improved by intraoperative epidural infusion (HR, 0.7; 95\% CI, 0.4 to $1.2 ; P=0.19$ ). These results are summarized in Tables 2 (OS) and 3 (CSS).

Analysis of the multivariable propensity score on the matched cohort revealed that POE was still associated with

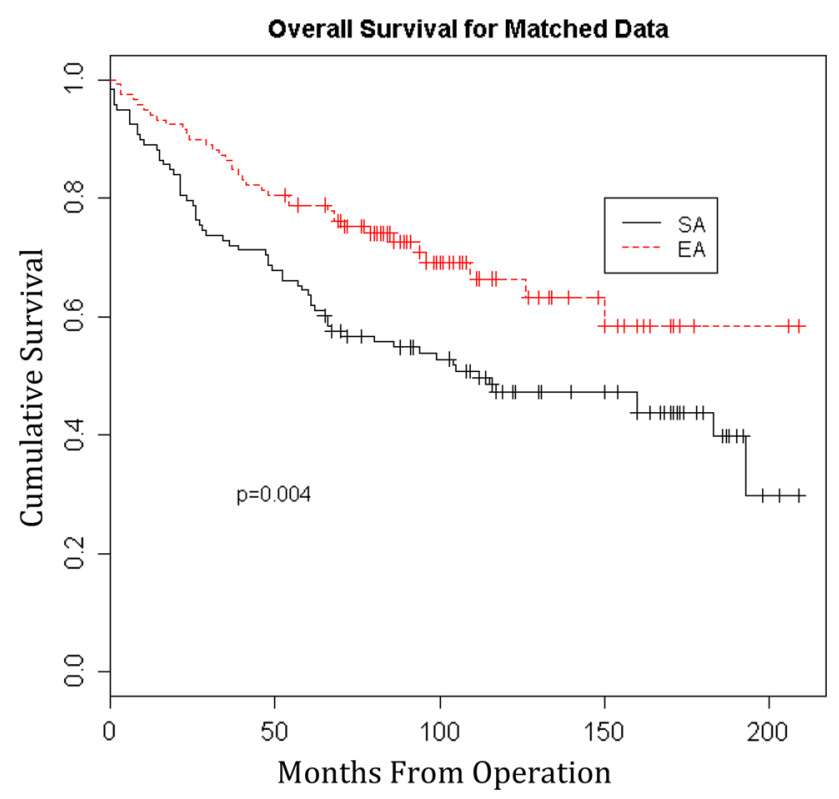

Fig. 1 Kaplan-Meier overall survival comparison of systemic analgesia $v s$ epidural analgesia in matched patients undergoing radical or partial nephrectomy for localized renal cell carcinoma significantly improved OS $(P=0.004)$ but not CSS $(P=0.22)$.

In secondary analyses, median intraoperative blood loss for patients in the SA group was $425 \mathrm{~mL} v s 300 \mathrm{~mL}$ in the EA group (95\% CI, 290 to 877; $P<0.001$ ), while the median hospital stay was five days in both groups $(P=0.14)$.

\section{Discussion}

Our study describes the outcomes after RCC surgery and use of POE in a single tertiary centre. The findings suggest an association between POE and improved OS after surgery for clinically localized RCC, but no statistically significant improvement in CSS. Baseline pathologic stage characteristics were statistically different between SA and EA groups, but given the retrospective nature of our study, this finding was not unexpected. Performing a multivariable matched analysis controlled for this difference and, not surprisingly, revealed that increasing pT-stage was inversely associated with OS and CSS. Age was found to be a predictor of OS but not CSS, while sex, race, ASA class, and pathologic Fuhrman grade had no effect on CSS or OS. Our OS rates are comparable with contemporary OS rates from other open RN and PN series in the setting of localized RCC. ${ }^{22,23}$ It is important to point out that all univariable and multivariable analyses of matched data exclude all patients who had a partial

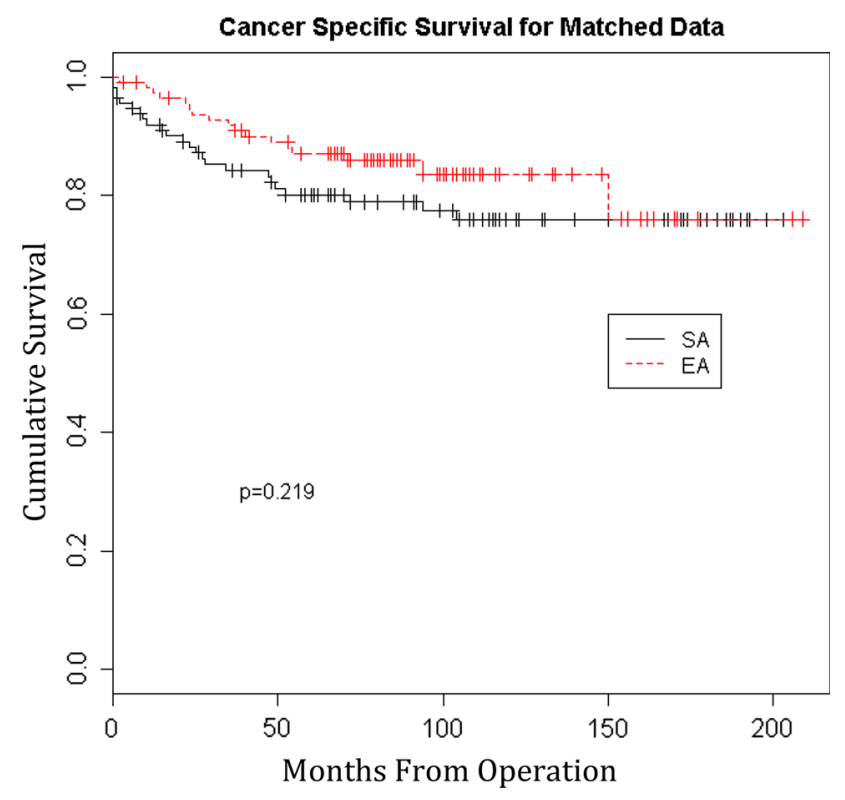

Fig. 2 Kaplan-Meier cancer-specific survival comparison of systemic analgesia vs epidural analgesia in matched patients undergoing radical or partial nephrectomy for localized renal cell carcinoma 
Table 2 Multivariable analysis of overall survival based on perioperative epidural status for matched groups

\begin{tabular}{lccr}
\hline Variable & $P$ Value & HR & $95 \%$ CI \\
\hline Received POE & 0.003 & 0.55 & 0.37 to 0.82 \\
Intraoperative Epidural Use & 0.006 & 0.56 & 0.41 to 0.86 \\
Age & $<0.001$ & 1.04 & 1.02 to 1.07 \\
Race (Caucasian $v s$ non-Caucasian) & 0.83 & 1.08 & 0.54 to 2.17 \\
Sex (female $v s$ male) & 0.77 & 1.06 & 0.72 to 1.56 \\
Year of Surgery & 0.001 & 0.91 & 0.85 to 0.96 \\
ASA Class (III-IV vs I-II) & 0.70 & 0.89 & 0.50 to 1.60 \\
Stage pT2 vs pT1 & 0.003 & 2.48 & 1.36 to 4.52 \\
Stage pT3 $v s$ pT1 & $<0.001$ & 3.08 & 1.98 to 4.80 \\
Fuhrman Grade (III-IV vs I-II) & 0.78 & 0.94 & 0.62 to 1.44 \\
\hline
\end{tabular}

ASA = American Society of Anesthesiologists; $\mathrm{CI}=$ confidence interval; $\mathrm{HR}=$ hazard ratio; $\mathrm{POE}=$ perioperative epidural; $\mathrm{pT}=$ pathologic T-stage

Table 3 Multivariable analysis of cancer-specific survival based on perioperative epidural status for matched groups

\begin{tabular}{lccc}
\hline Variable & $P$ Value & HR & $95 \%$ CI \\
\hline Received POE & 0.21 & 0.67 & 0.36 to 1.24 \\
Intraoperative Epidural Use & 0.19 & 0.70 & 0.38 to 1.22 \\
Age & 0.82 & 1.00 & 0.97 to 1.04 \\
Race (Caucasian $v s$ non-Caucasian) & 0.81 & 0.88 & 0.30 to 2.54 \\
Sex (female $v s$ male) & 0.74 & 1.11 & 0.60 to 2.05 \\
Year of Surgery & 0.01 & 0.90 & 0.81 to 0.96 \\
ASA Class (III-IV vs I-II) & 0.73 & 0.85 & 0.35 to 2.08 \\
Stage pT2 $v s$ pT1 & 0.01 & 3.82 & 1.36 to 10.74 \\
Stage pT3 $v s$ pT1 & $<0.001$ & 8.11 & 3.65 to 18.02 \\
Fuhrman Grade (III-IV vs I-II) & 0.22 & 1.58 & 0.77 to 3.24 \\
\hline ASA A
\end{tabular}

ASA = American Society of Anesthesiologists; $\mathrm{CI}=$ confidence interval; $\mathrm{HR}=$ hazard ratio; $\mathrm{POE}==$ perioperative epidural; $\mathrm{pT}=$ pathologic T-stage

nephrectomy, as no staging data were available for this subgroup. Extending the results of our univariable and multivariable matched analyses to patients with a partial nephrectomy may not be appropriate.

In the United States, RCC (the predominant form of kidney cancer in adults) incidence rates continue to rise, though a significant stage migration towards the detection of localized early-stage tumours has occurred. These patterns are consistent with reports of incidental diagnoses due to the increasing use of abdominal ultrasound and computed tomography imaging modalities. $^{24}$ With increased detection of localized renal masses, improved cure rates are attainable through surgical intervention, which is the mainstay of curative treatment.

The fact that cellular-mediated immunity is the primary defense mechanism against cancer cells is germane to our hypothesis. Both animal and human studies suggest that natural killer (NK) cell activity may play a critical role in determining disease-free survival after oncologic surgery. ${ }^{25}$
The possible interaction between surgery, anesthesia, cellular immunity, and cancer recurrence is complicated and has been studied in various tumour models. ${ }^{26}$

Intravenous anesthetics like propofol do not seem to inhibit growth of cancer cells, but they limit their invasion in a number of malignant cell models ${ }^{27-30}$ and seem to have a protective effect regarding development of metastases. ${ }^{31}$ In rats, ketamine and thiopental appear to suppress NK cells and increase the risk of cancer recurrence ${ }^{32}$; Midazolam contributes to immunosuppression in humans, ${ }^{33}$ while opioids inhibit humoral and cellular immune functions in humans, ${ }^{34}$ to cite several examples.

Renal cell carcinoma is an immunoresponsive cancer, exemplified by the use of interleukin-2 in cases of metastatic disease and occasionally resulting in complete remission in these patients. ${ }^{35}$ The immunoresponsivity of RCC begs the question whether a more efficient patient immune system in the perioperative period leads to better survival outcomes following cancer-related surgery. 
A novel study has evaluated the effect of epidural anesthesia on the occurrence of renal cancer in a subset of 30 patients (11 epidural, 19 non-epidural) from a larger multiorgan prospective randomized trial comparing POE with no POE at the time of oncologic surgery. Results of this study showed similar survival outcomes for both groups. ${ }^{36}$ Other investigators have analyzed post-surgical outcomes of various genitourinary malignancy interventions, with conflicting results. Biki et al. found that the recurrence of cancer following radical prostatectomy was $57 \%$ lower in patients treated with epidural anesthesia. ${ }^{37}$ Nevertheless, Mir et al. showed higher biochemical recurrence rates in males who received POE when undergoing radical prostatectomy $(P=0.012) .{ }^{38}$ Ours is a novel study representing a model of pure renal cell carcinoma.

Several groups have retrospectively studied the association between POE and improved survival in other cancers. While some found statistically significant associations between the use of POE and increased time to cancer recurrence and overall survival, ${ }^{39}$ others have not shown any survival benefit with utilization of POE for oncologic surgeries. ${ }^{40-42}$ A recent meta-analysis of 20 studies, analyzing outcomes of over 50,000 patients undergoing cancer-related surgery, concluded that regional anesthesia improves OS but not cancer recurrence rates when compared with general anesthesia alone $^{43}$-results that reflect our own.

As a result of conflicting evidence, a recent workshop from the British Journal of Anaesthesia produced a consensus statement regarding cancer and anesthesia. The group concluded that, "while the concept that anesthetic or analgesic technique might affect cancer outcomes is intriguing, there is currently insufficient evidence to support any change in clinical practice." ${ }^{44}$ Clearly, more level-1 evidence is needed in order to support or refute the hypothesis that effective POE anesthesia leads to better cancer-related survival outcomes in the context of oncologic surgery, and randomized trials are currently underway. ${ }^{45}$

Our study identified an OS benefit associated with the use of POE with no CSS benefit. This finding, in our opinion, is somewhat puzzling, since the proposed mechanism of any attributed survival benefit is the improved immune function and immune surveillance of micrometastatic disease associated with POE analgesia. Still, epidural use was associated with a non-statistically significant HR of 0.7 with regard to CSS. This finding raises the question whether methodological shortcomings and bias partially neutralized any positive effect of epidural use. In this regard, a type-II error cannot be ruled out.

In fact, this dichotomous finding is not without precedent. In one of the largest series, Cummings et al. retrospectively analyzed 42,000 patients from the Surveillance, Epidemiology, and End Results database who underwent open colectomy for nonmetastatic colorectal cancer and calculated survival based on POE status. Interestingly, an association was observed between epidural use and improved survival (HR, 0.91; 95\% CI, 0.87 to 0.94). Nevertheless, no reduction in cancer recurrence was found (odds ratio, 1.05; 95\% CI, 0.95 to $1.15)^{46}$

In a secondary analysis, we found a statistically significant reduction in intraoperative blood loss in the POE group - a finding consistent with a recently published meta-analysis. ${ }^{47}$ Whether epidural use has an indirect, specific effect on survival outcomes via better hemodynamic control and decreased intraoperative blood loss remains to be elucidated.

In addition, we found no difference in hospital stay between the groups. The results in the literature regarding the effect of epidural analgesia and length of stay are inconsistent, ${ }^{48,49}$ and such analysis is lacking in the context of urologic surgery. The answer to this question will require prospective studies.

Our study has several limitations. The retrospective nature lends itself to various inherent biases. Patients were not randomly assigned to either group and postoperative follow-up was not standardized, thus potentially introducing selection and confounding biases inherent in observational analyses. Second, specific cause of death was not available for 28/206 deaths, and we did not compare the characteristics of these 28 patients with the patients included in the survival analysis; thus, this is a potential source of bias. We speculate that we might have observed a significant difference in CSS, in addition to OS, had this missing information been available in our study population. In addition, epidural opioid dosing information, rescue systemic opioid analgesia requirements for EA patients and systemic narcotic use information for SA patients, was not uniformly available and is a potential confounder of our study. Furthermore, pre- and postoperative patient comorbidities, such as reduced glomerular filtration rate, frailty, and other concurrent diseases, may have confounded our results. Additionally, tyrosine kinase inhibitors, the mainstay of treatment for metastatic RCC, were not available for the majority of patients in our cohort as they were treated before these drugs became widely available. Nevertheless, we did not control for the use of these drugs and other treatment protocols, thus potentially confounding our results. For example, Enhanced Recovery After Surgery (ERAS) protocols are a recent evolution of pre- and post-surgical care and are now implemented commonly for major intra-abdominal surgeries. Nevertheless, ERAS protocols were not uniformly implemented at our institution during the study period. 
As with all retrospective studies, our ability to adjust for potential biases is limited to the available data. Although we attempted to standardize our cohorts (i.e., we excluded patients with positive surgical margins, non-malignant histology, evidence of clinical or pathologic lymph node involvement, evidence of clinical or pathologic metastatic disease), we eliminated a large number of patients from the original database to achieve this end, and this limitation is noteworthy. Despite the relatively homogeneous characteristics of our study groups, residual bias due to uncontrolled variables may remain. Consequently, the associations we report should not be considered evidence of a causal relationship, which will more reliably be derived from prospective randomized trials.

Despite these limitations, the strengths of our study bear consideration. This analysis represents one of the largest comparative epidural series to date in the context of RCC surgery and subsequent survival. We adhered to strict inclusion and exclusion criteria in order to capture patients without evidence of clinical, pathologic, or radiographic residual disease immediately following PN or RN. Finally, the median follow-up of 77 months is a considerable achievement.

\section{Conclusion}

Our retrospective analysis suggests no significant CSS benefit, but a significant OS advantage associated with POE analgesia in patients undergoing open surgical resection of localized RCC. Our results also show that POE confers an intraoperative blood loss advantage. In our view, the decision to use POE in open RCC surgery should be based primarily on other objectives, such as the provision of superior analgesia, patient satisfaction, and decreased side effects of systemic opioids. Further basic science and translational work is required to identify differences in tumour biology in response to POE compared with $\mathrm{SA}$ and to delineate the underlying mechanism(s) of action of epidural anesthesia on the proliferation of cancer cells.

\section{Conflicts of interest None declared.}

Editorial responsibility This submission was handled by Dr. Steven Backman, Associate Editor, Canadian Journal of Anesthesia.

\footnotetext{
Authors Contributions Evan Kovac, Hesham Elsharkawy, and Amr Fergany contributed substantially to the conception and design of the study. Evan Kovac, Hesham Elsharkawy, Homayoun Zargar, and Farhad Firoozbakhsh contributed substantially to the acquisition and analysis of data. Evan Kovac, Hesham Elsharkawy, and Farhad Firoozbakhsh contributed substantially to the interpretation of data and drafting the article.
}

\section{References}

1. Siow WY, Yip SK, Ng LG, Tan PH, Cheng WS, Foo KT. Renal cell carcinoma: incidental detection and pathological staging. J R Coll Surg Edinb 2000; 45: 291-5.

2. Hashimoto M, Tanaka F, Yoneda $K$, et al. Significant increase in circulating tumour cells in pulmonary venous blood during surgical manipulation in patients with primary lung cancer. Interact Cardiovasc Thorac Surg 2014; 18: 775-83.

3. Juratli MA, Sarimollaoglu M, Siegel ER, et al. Real-time monitoring of circulating tumor cell release during tumor manipulation using in vivo photoacoustic and fluorescent flow cytometry. Head Neck 2014; 36: 1207-15.

4. Chu H, Wang M, Yan F, et al. Polymorphisms in the IL-13 and IL-4R genes are associated with the development of renal cell carcinoma. Ann Oncol 2012; 23: 2114-21.

5. Van Poppel H, Joniau S, Van Gool SW. Vaccine therapy in patients with renal cell carcinoma. Eur Urol 2009; 55: 1333-42.

6. Wang ZX, Li JL, Cao JX, et al. Cytokine-induced killer cells in the treatment of patients with renal cell carcinoma: a pooled meta-analysis. Immunotherapy 2014; 6: 787-95.

7. Pyrhonen S, Salminen E, Ruutu M, et al. Prospective randomized trial of interferon alfa-2a plus vinblastine versus vinblastine alone in patients with advanced renal cell cancer. J Clin Oncol 1999; 17: 2859-67.

8. Yang JC, Sherry RM, Steinberg SM, et al. Randomized study of high-dose and low-dose interleukin-2 in patients with metastatic renal cancer. J Clin Oncol 2003; 21: 3127-32.

9. Ahlers $O$, Nachtigall I, Lenze J, et al. Intraoperative thoracic epidural anaesthesia attenuates stress-induced immunosuppression in patients undergoing major abdominal surgery. $\mathrm{Br} \mathrm{J}$ Anaesth 2008; 101: 781-7.

10. Beilin B, Shavit $Y$, Trabekin E, et al. The effects of postoperative pain management on immune response to surgery. Anesth Analg 2003; 97: 822-7.

11. Koltun WA, Bloomer MM, Tilberg AF, et al. Awake epidural anesthesia is associated with improved natural killer cell cytotoxicity and a reduced stress response. Am J Surg 1996; 171: 68-72; discussion 72-3.

12. Yang C, Chang H, Zhang T, Liang C, Li E. Pre-emptive epidural analgesia improves post-operative pain and immune function in patients undergoing thoracotomy. ANZ J Surg 2014; 85: 472-7.

13. Gottschalk A, Sharma S, Ford J, Durieux ME, Tiouririne M. Review article: the role of the perioperative period in recurrence after cancer surgery. Anesth Analg 2010; 110: 1636-43.

14. Snyder GL, Greenberg S. Effect of anaesthetic technique and other perioperative factors on cancer recurrence. $\mathrm{Br} \mathrm{J}$ Anaesth 2010; 105: 106-15.

15. Ching CB, Lane BR, Campbell SC, Li J, Fergany AF. Five to 10year followup of open partial nephrectomy in a solitary kidney. $\mathrm{J}$ Urol 2013; 190: 470-4.

16. Fuhrman SA, Lasky LC, Limas C. Prognostic significance of morphologic parameters in renal cell carcinoma. Am J Surg Pathol 1982; 6: 655-63.

17. Edge SB, Compton CC. The American Joint Committee on Cancer: the 7th edition of the AJCC cancer staging manual and the future of TNM. Ann Surg Oncol 2010; 17: 1471-4.

18. Chow WH, Shuch B, Linehan WM, Devesa SS. Racial disparity in renal cell carcinoma patient survival according to demographic and clinical characteristics. Cancer 2013; 119: 388-94.

19. de Cassio Zequi S, de Campos EC, Guimarães GC, Bachega W $J r$, da Fonseca FP, Lopes A. The use of the American Society of Anesthesiology Classification as a prognostic factor in patients with renal cell carcinoma. Urol Int 2010; 84: 67-72. 
20. Minardi D, Lucarini G, Mazzucchelli $R$, et al. Prognostic role of Fuhrman grade and vascular endothelial growth factor in pT1a clear cell carcinoma in partial nephrectomy specimens. J Urol 2005; 174(4 Pt 1): 1208-12.

21. Onishi T, Oishi Y, Goto H, Yanada S, Abe $K$. Gender as a prognostic factor in patients with renal cell carcinoma. BJU Int 2002; 90: 32-6.

22. Fergany AF, Hafez, KS, Novick AC. Long-term results of nephron sparing surgery for localized renal cell carcinoma: 10-year followup. J Urol 2000; 163: 442-5.

23. Russo P, Jang TL, Pettus JA, et al. Survival rates after resection for localized kidney cancer: 1989 to 2004. Cancer 2008; 113: 8496.

24. Kane CJ, Mallin K, Ritchey J, Cooperberg MR, Carroll PR. Renal cell cancer stage migration: analysis of the National Cancer Data Base. Cancer 2008; 113: 78-83.

25. Gross E, Sunwoo JB, Bui JD. Cancer immunosurveillance and immunoediting by natural killer cells. Cancer J 2013; 19: 483-9.

26. Gaspani L, Bianchi M, Limiroli E, Panerai AE, Sacerdote P. The analgesic drug tramadol prevents the effect of surgery on natural killer cell activity and metastatic colonization in rats. J Neuroimmunol 2002; 129: 18-24.

27. Miao $Y$, Zhang $Y$, Wan $H$, Chen $L$, Wang $F$. GABA-receptor agonist, propofol inhibits invasion of colon carcinoma cells. Biomed Pharmacother 2010; 64: 583-8.

28. Wang P, Chen J, Mu LH, Du QH, Niu XH, Zhang MY. Propofol inhibits invasion and enhances paclitaxel- induced apoptosis in ovarian cancer cells through the suppression of the transcription factor slug. Eur Rev Med Pharmacol Sci 2013; 17: 1722-9.

29. Хu YB, Du $Q H$, Zhang $M Y$, Yun $P$, He $C Y$. Propofol suppresses proliferation, invasion and angiogenesis by down-regulating ERK-VEGF/MMP-9 signaling in Eca-109 esophageal squamous cell carcinoma cells. Eur Rev Med Pharmacol Sci 2013; 17: 2486-94.

30. Ye Z, Jingzhong L, Yangbo L, Lei C, Jiandong Y. Propofol inhibits proliferation and invasion of osteosarcoma cells by regulation of microRNA-143 expression. Oncol Res 2013; 21: 201-7.

31. Inada T, Kubo K, Kambara T, Shingu K. Propofol inhibits cyclooxygenase activity in human monocytic THP-1 cells. Can J Anesth 2009; 56: 222-9.

32. Shakhar $G$, Ben-Eliyahu $S$. In vivo beta-adrenergic stimulation suppresses natural killer activity and compromises resistance to tumor metastasis in rats. J Immunol 1998; 160: 3251-8.

33. Galley HF, Dubbels AM, Webster NR. The effect of midazolam and propofol on interleukin-8 from human polymorphonuclear leukocytes. Anesth Analg 1998; 86: 1289-93.

34. Yeager MP, Colacchio TA, Yu CT, et al. Morphine inhibits spontaneous and cytokine-enhanced natural killer cell cytotoxicity in volunteers. Anesthesiology 1995; 83: 500-8.

35. Rosenberg SA, Yang JC, White DE, Steinberg SM. Durability of complete responses in patients with metastatic cancer treated with high-dose interleukin-2: identification of the antigens mediating response. Ann Surg 1998; 228: 307-19.
36. Myles PS, Peyton P, Silbert B, et al. Perioperative epidural analgesia for major abdominal surgery for cancer and recurrencefree survival: randomised trial. BMJ 2011; 342: d1491.

37. Biki B, Mascha E, Moriarty DC, Fitzpatrick JM, Sessler DI, Buggy DJ. Anesthetic technique for radical prostatectomy surgery affects cancer recurrence: a retrospective analysis. Anesthesiology 2008; 109: 180-7.

38. Mir MC, Joseph B, Zhao R, Bolton DM, Gyomber D, Lawrentschuk $N$. Effectiveness of epidural versus alternate analgesia for pain relief after radical prostatectomy and correlation with biochemical recurrence in men with prostate cancer. Res Rep Urol 2013; 5: 139-45.

39. Hiller JG, Hacking MB, Link EK, Wessels KL, Riedel BJ. Perioperative epidural analgesia reduces cancer recurrence after gastro-oesophageal surgery. Acta Anaesthesiol Scand 2014; 58: 281-90.

40. Cao L, Chang $Y$, Lin $W$, et al. Long-term survival after resection of hepatocelluar carcinoma: a potential risk associated with the choice of postoperative analgesia. Anesth Analg 2014; 118: 1309-16.

41. Cata JP, Gottumukkala V, Thakar D, Keerty D, Gebhardt R, Liu $D D$. Effects of postoperative epidural analgesia on recurrencefree and overall survival in patients with nonsmall cell lung cancer. J Clin Anesth 2014; 26: 3-17.

42. Cata JP, Hernandez M, Lewis VO, Kurz A. Can regional anesthesia and analgesia prolong cancer survival after orthopaedic oncologic surgery? Clin Orthop Relat Res 2014; 472: 1434-41.

43. Sun $\mathrm{Y}, \mathrm{Li} \mathrm{T}$, Gan TJ. The effects of perioperative regional anesthesia and analgesia on cancer recurrence and survival after oncology surgery: a systematic review and meta-analysis. Reg Anesth Pain Med 2015; 40: 589-98.

44. Buggy DJ, Borgeat A, Cata J, et al. Consensus statement from the BJA Workshop on Cancer and Anaesthesia. B J Anaesth 2015; 114: 2-3.

45. Sessler DI, Ben-Eliyahu S, Mascha EJ, Parat MO, Buggy DJ. Can regional analgesia reduce the risk of recurrence after breast cancer? Methodology of a multicenter randomized trial. Contemp Clin Trials 2008; 29: 517-26.

46. Cummings $K C$ 3rd, Xu F, Cummings LC, Cooper GS. A comparison of epidural analgesia and traditional pain management effects on survival and cancer recurrence after colectomy: a population-based study. Anesthesiology 2012; 116: 797-806.

47. Richman JM, Rowlingson AJ, Maine DN, Courpas GE, Weller $J F, W u C L$. Does neuraxial anesthesia reduce intraoperative blood loss? A meta-analysis. J Clin Anesth 2006; 18: 427-35.

48. de Leon-Casasola OA, Parker BM, Lema MJ, Groth RI, OrsiniFuentes $J$. Epidural analgesia versus intravenous patientcontrolled analgesia. Differences in the postoperative course of cancer patients. Reg Anesth 1994; 19: 307-15.

49. Marret E, Remy C, Bonnet F, Postoperative Pain Forum Group. Meta-analysis of epidural analgesia versus parenteral opioid analgesia after colorectal surgery. Br J Surg 2007; 94: 665-73. 